Disponível em:

http://editora.unoesc.edu.br/index.php/race

Race, Joaçaba, v. 15, n. 3, p. 969-1006, set./dez. 2016

\title{
DIFERENTES BENEFÍCIOS DA GOVERNANÇA NA GESTÃO DE ORGANIZAÇÕES DE INTERESSE PÚBLICO E PRIVADO: O CASO DA REDE BIODIESEL SERGIPE
}

Different benefits governance in the public interest of management and private organizations: the Network case Biofuel Sergipe

Vitor Hugo da Silva Vaz

E-mail: vitorhugovaz22@hotmail.com

Mestre em Administração e Doutorando em Ciência da Propriedade Intelectual pela

Universidade Federal de Sergipe;

Coordenador do Projeto de Implantação do Centro Vocacional Tecnológico do SergipeTec.

Maria Elena Leon Olave

E-mail: mleonolave@gmail.com

Doutora em Engenharia de Produção pela Universidade de São Paulo; Mestre em

Engenharia de Produção pela Escola Politécnica da Universidade de São Paulo; Professora adjunta do Departamento de Administração da Universidade Federal de Sergipe e Coordenadora do Programa de Pós-Graduação em Administração. Endereço para contato: Avenida Marechal Rondon, s/n, Jardim Rosa Elze, 49100000, São Cristóvão, Sergipe, Brasil.

Osiris Ashton Vital Brazil

E-mail: ashton.brazil@gmail.com

Doutor em Engenharia de Processos pela Universidade Tiradentes; Mestre em Regulação da Indústria de Energia pela Universidade Salvador - Laureate International Universities.

Artigo recebido em 15 de abril de 2015. Aceito em 20 de maio de 2016. 


\section{Resumo}

A governança de uma rede de empresas pode apresentar diferentes benefícios para as organizações participantes. Porém, nem sempre os estudos sobre governança têm foco em como as características das organizações podem influenciar os benefícios gerados. Assim, no presente trabalho teve-se o objetivo de analisar como a governança dessa rede de empresas pode apresentar diferentes contribuições à gestão em organizações parceiras. Metodologicamente, foi realizado um estudo de caso único em uma rede de empresas que tinha como objetivo central estruturar a cadeia de produção e o uso do biodiesel no Estado de Sergipe (Rede Biodiesel Sergipe). A coleta de informações foi realizada por meio de um roteiro de entrevista semiestruturada realizado com representantes de organizações públicas e privadas. Os resultados mostraram que, em grandes organizações, como um banco e uma instituição governamental, foi evidente o desenvolvimento de novos produtos, novos grupos de pesquisas e metodologias de gestão. Entretanto, os benefícios gerados pela governança foram mais evidentes em uma cooperativa de agricultura familiar, que obteve a reorganização do processo produtivo, a estruturação administrativa, a geração de novos negócios e a implementação de políticas públicas para a erradicação da pobreza e a evolução do pequeno agricultor. Como contribuição teórica, com o estudo possibilitou-se mostrar que, além dos benefícios, as características atribuídas a cada instituição ofereceram benefícios distintos aos participantes da Rede. Nesse caso, estudos futuros sobre a governança de redes devem considerar o perfil das instituições participantes, considerando-se os benefícios distintos proporcionados.

Palavras-chave: Benefícios. Governança. Organizações. Rede Biodiesel. Sergipe.

\section{Abstract}

The governance of a network of companies can provide different benefits to the participating organizations. But not always the studies on governance focuses on the features of the organizations can influence the generated benefits. Thus, this study aims to analyze how the governance of the network may have different contributions to management in partner organizations. Methodologically, there was a single case study of a network of companies that had as main objective to structure the chain of production and use of biodiesel in the state of Sergipe (Biodiesel Sergipe Network). Data collection was performed using a semi-structured interview guide held with representatives of public and private organizations. The results showed that, in large organizations, such as a bank and a government institution, the development of new products, research groups and methodologies management was evident. However, the benefits generated by governance were more evident in a family farming cooperative that got the reorganization of the production process, administrative structure, generating new business and implementation of public policies for poverty eradication and development of the small farmer. As a theoretical contribution, it enabled the study show that, in addition to the benefits, features assigned to each institution offered distinct benefits to Network participants. In this 
case, future studies on governance networks should consider the profile of the participating institutions in view of the distinct benefits provided.

Keywords: Benefits. Governance. Organizations. Biofuel Network. Sergipe.

\section{INTRODUÇÃO}

Alguns fenômenos recentes como o agravamento das catástrofes climáticas, as crises políticas no Oriente Médio e o crescimento econômico da China têm posto em xeque o modelo de desenvolvimento adotado pelas civilizações modernas, baseado no petróleo como principal fonte de energia (CAMPOS; CARMELIO, 2006). A consequência disso é a busca por alternativas renováveis e menos poluentes que possuem um importante papel na agricultura, seja pela produção de matérias-primas seja pelo aproveitamento de resíduos da natureza para a geração de energia (VIEIRA, 2006).

Uma das fontes alternativas para a produção de energia renovável é o biodiesel ao qual se utilizam como matérias-primas plantas oleaginosas (soja, girassol, dendê, mamona, canola, sorgo, pinhão-manso, amendoim), além de óleos e gorduras residuais, como óleo de fritura e sebo bovino, suíno e de aves (CAMPOS; CARMELIO, 2006). No caso dos óleos provenientes de fritura ou de gordura animal, o aproveitamento também garante a diminuição da poluição em rios e mares.

O biodiesel é um combustível renovável proveniente de biomassa para uso em motores à combustão comum, como em caminhões e ônibus, e que pode substituir parcial ou totalmente o diesel, um combustível de origem fóssil (BRASIL, 2005a). Nesse processo, segundo Sachs (2005), o Brasil assume um importante papel no desenvolvimento de uma "nova civilização baseada na biomassa”, em detrimento dos combustíveis fósseis.

A regulamentação para a produção de biodiesel no Brasil ocorreu pela Lei n. 11.097 de 2005, que introduziu o Programa Nacional de Produção e uso de Biodiesel (PNPB), e estabeleceu as condições para produção, comercialização e uso do biodiesel no País, com a obrigatoriedade da participação da agricultura familiar e/ou suas representações (cooperativas, associações e federações) na cadeia de suprimento (ABRAMOVAY; MAGALHÃES, 2007).

Em Sergipe foi criada a Rede Biodiesel Sergipe, que nasceu das articulações de várias instituições públicas e privadas na tentativa de responder aos Governos do Estado e Federal como se engajar ao Programa Nacional de Produção de Biodiesel (PNPB) em 2007 (VITAL BRAZIL et al., 2008). 
As redes formadas entre empresas são componentes fundamentais para o desenvolvimento das organizações (CASTELLS, 1999). Nesse contexto, a análise de redes interorganizacionais tem sido objeto de amplas discussões dentro do campo de estudos organizacionais pelo fato de as redes serem muito importantes na vida econômica e facilitarem a complexa interdependência transacional e cooperativa entre organizações (BALESTRIN; VARGAS, 2002).

Em relação às redes interorganizacionais, a maior parte da literatura não aborda, explicitamente, o processo de formação da governança, entendida como o exercício de autoridade, controle, administração e poder de governar. A razão mais óbvia é que as redes são compostas por organizações autônomas e, portanto, tratam essencialmente dos resultados de esforços cooperativos (PROVAN; KENIS, 2008).

A governança de uma rede de empresas pode apresentar diferentes benefícios para as organizações participantes (RODRIGUES; MALO, 2006; HUMPHREY; SCHMITZ, 2001; CRUZ; MARTINS; QUANDT, 2008; FITTIPALDI; DONAIRE, 2009). Porém, nem sempre os estudos sobre governança têm foco em como as características das organizações podem influenciar os benefícios gerados pela governança. Dessa forma, de acordo com Provan e Kenis (2008), é necessário que existam estudos que mostrem como a governança é exercida em uma rede, e quais resultados essas relações podem gerar para o mercado e para a sociedade.

Assim, neste estudo teve-se como objetivo analisar como a governança da Rede Biodiesel Sergipe pode apresentar diferentes contribuições à gestão em organizações parceiras. Especificamente, foi realizada a caracterização das organizações participantes da Rede e analisadas as influências da governança desta na gestão das organizações participantes; por fim, foi analisada a influência das características na gestão de cada organização. A seguir, apresenta-se o referencial teórico adotado na pesquisa.

\section{REFERENCIAL TEÓRICO}

Nesta seção, o referencial teórico é apresentado destacando-se as diferentes definições sobre governança, suas tipologias, especialmente a governança de redes de empresas e os benefícios gerados a organizações participantes.

\subsection{DEFINIÇÕES SOBRE GOVERNANÇA}

Segundo Montenegro (2013), na área da Administração, é comum associar a palavra governança à governança corporativa. Entretanto, nem todos os estudos existentes abrangem apenas a governança corporativa. 
Para Rhodes (1996), o termo governança é “popular, mas impreciso” e, por esse fato, possui uma diversidade de significados que, geralmente, confunde-se com governo. Dessa forma, segundo Finer (1970 apud MONTENEGRO, 2013), é necessário diferenciar governança de governo, que pode ser entendido das seguintes formas:

a) A atividade ou processo de "governar" ou "governança";

b) Uma condição ou regra;

c) Pessoas encarregadas e com o dever de "governar" ou "governadores";

d) A forma, método ou sistema pelo qual uma determinada sociedade é "governada”.

De acordo com Rhodes (1996), a governança significa uma mudança no sentido do governo, referindo-se a um novo processo de governar, a uma alteração de condição ou de regras ordenadas, ou a um novo método pelo qual a sociedade é governada.

Rhodes (2007) destaca, também, que um ponto central da diferenciação de governança e de governo está, principalmente, na função da governança em abranger tanto organizações públicas quanto privadas.

Provan e Kenis (2008) associam a governança às atividades para o financiamento e as funções de fiscalização dos órgãos governamentais, especialmente, as de organizações privadas que tenham sido contratadas para prestar serviços públicos.

Pelo fato de existirem tais dúvidas sobre o termo governança, Correia e Amaral (2006) afirmam que não se apresentou uma definição única e universal para o termo, o que contribuiu para o não estabelecimento de um quadro teórico sobre o tema, considerando-se que existem várias correntes teóricas as quais explanam sobre o tema (CORNFORTH, 2004). A fim de se estabelecer uma definição simplificada, Pires et al. (2013) define governança da seguinte forma:

[...] conjunto de elementos institucionais, formalizados ou não, que estabelecem a regulação das relações entre atores públicos, privados e da sociedade civil (empresas, associações, sindicatos, poder público, ONGs) em torno de um planejamento ou projeto de desenvolvimento, ou mesmo na busca por resolver algum problema socioeconômico inédito em âmbito local, regional, nacional ou internacional. 
Apesar de a governança ser discutida por diferentes autores (RHODES, 1996, 2007, 2012; PROVAN; KENIS, 2008; SANTOS, 1997; OLIVEIRA et al., 2011) e ser vista em diferentes perspectivas teóricas (CORNFORTH, 2004; RODRIGUES; MALO, 2006), é necessário identificar o tipo de governança que será exercida. Nesse sentido, Humphrey e Schmitz (2000) destacam quatro tipos de governança, sendo elas: governança de mercado, redes, quase hierárquica e hierárquica. No Quadro 1, é possível visualizar os tipos de governança e seus determinantes.

Quadro 1 - Tipos e determinantes para a governança

\begin{tabular}{|l|l|}
\hline \multicolumn{1}{|c|}{$\begin{array}{c}\text { Tipos de } \\
\text { governança }\end{array}$} & \multicolumn{1}{c|}{ Determinantes } \\
\hline $\begin{array}{l}\text { Mercado com limite } \\
\text { definido }\end{array}$ & $\begin{array}{l}\text { Não há colaboração entre os compradores e os produtores para a definição } \\
\text { de determinado produto. Nesse caso, o produto pode ser padronizado, ou o } \\
\text { produtor pode definir o produto sem considerar os desejos dos clientes. Isso } \\
\text { representa baixos riscos para o comprador. }\end{array}$ \\
\hline Redes & $\begin{array}{l}\text { A relação de cooperação funciona de forma mais igualitária entre comprado- } \\
\text { res e vendedores. Nesse caso, os dois podem definir o produto ofertado e, por } \\
\text { esse fato, minimizar riscos relacionados às transações. }\end{array}$ \\
\hline Quase hierárquica & $\begin{array}{l}\text { Existe um grande controle do comprador sobre o vendedor. Nesse caso, o } \\
\text { comprador define o produto, mas pode sofrer no caso de o vendedor não } \\
\text { conseguir cumprir os compromissos estabelecidos. }\end{array}$ \\
\hline Hierárquica & $\begin{array}{l}\text { O comprador tem prioridade tanto no produto que será adquirido quanto na } \\
\text { tecnologia que será empregada no processo de produção. Nesse caso, mesmo } \\
\text { existindo influência no processo produtivo, o risco do não cumprimento de }\end{array}$ \\
\hline
\end{tabular}

Fonte: adaptado de Humphrey e Schmitz (2000).

Nesta pesquisa, o tipo de governança estudada foi o de uma rede de instituições. Porém, em vários estudos sobre redes o assunto está relacionado ao comportamento oportunista das diferentes instituições que compõem um grupo de parceiros (WILLIAMSOM, 1981).

A governança de redes é considerada um papel crítico (EISENHARDT, 1989), o que contradiz o determinante para o estabelecimento da governança em redes no estudo de Humphrey e Schmitz (2000), em razão da complexidade existente nas relações entre diferentes organizações que podem possuir objetivos, tamanhos e segmentos diferentes, influenciando o tipo de governança que será pactuada. 


\subsection{A GOVERNANÇA DE REDES}

Segundo Lopes e Baldi (2009), por meio dos estudos sobre governança de redes se busca compreender os mecanismos institucionais pelos quais os relacionamentos interorganizacionais são iniciados, negociados, desenhados, coordenados, monitorados, adaptados e terminados. Os autores, ainda, destacam que os estudos sobre a governança em rede, de longa data, fazem parte das pesquisas econômicas e gradativamente são incorporados aos estudos sobre organizações.

De forma geral, a governança tem por finalidade manter uma rede de forma estável e permanente, exercendo o papel de reguladora para diminuir os conflitos e permitir que todas as empresas desempenhem suas funções, trabalhando para o bem geral e protegendo a rede de possíveis ameaças (FITTIPALDI; DONAIRE, 2009). Porém, de acordo com Provan e Kenis (2008), mesmo existindo uma grande quantidade de estudos sobre redes de empresas, principalmente os que têm foco nas relações de cooperação, pouca atenção tem sido dispensada aos estudos sobre governança de redes. Segundo os autores, uma das justificativas dadas para a pouca quantidade de estudos é que as redes são compostas por organizações autônomas e, portanto, tratam essencialmente dos resultados de esforços cooperativos.

No contexto do uso da governança para a estruturação de redes, Kwasnicka (2006) realizou um estudo sobre a importância de uma estrutura organizacional formal comparando duas empresas em uma rede. A autora concluiu que, apesar de não existir um padrão para a estruturação da governança em uma rede, é possível fazer um desenho desta no qual os elementos estruturais são perceptíveis pelos parceiros e se sustentam nos relacionamentos estabelecidos entre as empresas participantes.

Souza e Quandt (2007) analisaram a estrutura de governança em uma rede de empresas do terceiro setor para identificar se o processo de governança possibilitou a redução de níveis de controle formal entre as instituições. Os autores diagnosticaram que, em ambientes cooperativos, a governança fez com que a rede apresentasse um discreto aumento na tendência de hierarquização nas atividades de coordenação de execução dos projetos e de controle sobre os fluxos de informação e acesso aos recursos, além de um pequeno aumento no controle formal das atividades.

Pardini, Alves e Gonçalves (2010) analisaram estruturação, gestão e governança gestora nas redes de cooperação do segmento de varejo farmacêutico. Os autores constataram, por meio do estudo comparativo de dois casos, que as redes utilizaram instrumentos normativos de governança para o cumprimento das responsabilidades e deveres de seus associados, e que as instituições interessadas na rede foram 
atraídas pela grande quantidade de contribuições que ela poderia proporcionar, como: compartilhamento de compras, experiências de gestão e informações.

No estudo de Zylbersztajn e Farina (2010) foi realizada uma investigação de como os níveis horizontal e vertical de coordenação são conectados em dois casos de arquitetura de redes nas relações agroindustriais. Os resultados mostraram que houve impactos tanto positivos quanto negativos nos resultados estabelecidos pelos parceiros, influenciados pela arquitetura adotada por cada rede, principalmente em relação à elevação dos custos nas transações.

Wegner (2012) estudou a governança como elemento de sustentação de redes horizontais de empresas, descrevendo os mecanismos adotados por redes de grande porte na Alemanha e suas mudanças ao longo do tempo. O autor constatou que as estruturas adotadas pelas duas redes pesquisadas sofreram alterações no poder de articulação se adequando às necessidades das empresas, e, assim, a governança adotada foi transitória.

De acordo com Provan e Kenis (2008), as formas de governança de rede podem ser classificadas em três dimensões diferentes: as compartilhadas, as exercidas por uma instituição e as exercidas por uma instituição contratada.

Nos três tipos de governança de redes apresentados anteriormente a evolução poderá ocorrer de formas diferentes (PROVAN; KENIS, 2008). Nesse caso, a evolução é mais provável em redes cuja governança é compartilhada, pois haverá uma flexibilidade maior em relação às relações estabelecidas entre as organizações. Nos demais tipos de governança a evolução da rede será mais difícil, principalmente em decorrência da existência de grande quantidade de relações formais, o que em longo prazo poderá travar o desenvolvimento da rede.

A partir das discussões sobre a estrutura de governança de uma rede, foi possível perceber que os estudos existentes sobre governança em redes, em sua maioria, têm foco nos benefícios adquiridos pelas organizações participantes. Nesse sentido, na seção a seguir são apresentados alguns estudos sobre os benefícios gerados pela governança em redes de empresas.

\subsection{BENEFÍCIOS PROPORCIONADOS PELA GOVERNANÇA}

Apesar de ainda carecer de um quadro teórico e haver a necessidade de trabalhos teóricos e empíricos para desenvolvimento, evolução e crítica (RODRIGUES; MALO, 2006), a governança tem sido alvo de crescentes discussões em virtude da 
grande importância para os diferentes setores (HUMPHREY; SCHMITZ, 2001), pois pode oferecer às organizações as seguintes contribuições:

a) acesso ao mercado: mesmo quando os países desenvolvidos retiram as barreiras comerciais, os produtores dos países em desenvolvimento não ganham automaticamente acesso ao mercado, porque as cadeias que os produtores alimentam, muitas vezes, são regidas por um número limitado de compradores;

b) o caminho mais rápido para a aquisição de capacidades de produção: os produtores que obtêm acesso às empresas em cadeias produtivas tendem a se encontrar em uma curva de aprendizagem e, consequentemente, obter vantagem diante da concorrência;

c) funil de assistência técnica: agências multilaterais e bilaterais há décadas buscavam encontrar formas de prestação de assistência técnica eficaz para os produtores dos países em desenvolvimento.

Para Pires et al. (2013), a governança tem a função central de proporcionar a organização de ações conjuntas entre instituições públicas, privadas e da sociedade civil (empresas, associações, sindicatos, poder público, ONGs), norteada por planos ou projetos preestabelecidos para desenvolver ações de cunho econômico e/ou social em determinada localidade. Nesse sentido, alguns estudos sobre as contribuições da governança em redes de instituições foram elaborados em todo o País.

Cruz, Martins e Quandt (2008), por exemplo, realizaram um estudo sobre a governança de uma rede de catadores de Curitiba, PR, e buscaram caracterizar o modelo de governança adotado pela rede que apresentou uma mescla entre modelos de governança comunitária e de parcerias. A adoção de tais modelos contribuiu para o estabelecimento de relações comerciais e a promoção e criação de capitais intangíveis.

Fittipaldi e Donaire (2009), em estudo sobre a identificação da governança exercida em uma rede de negócios do setor editorial de revistas de São Paulo, destacaram benefícios como: redução de custos, eliminação de empresas ineficientes, regularidade e planejamento no processo de produção, melhora na gestão do negócio, perpetuação do negócio, alto grau de especialização, maior divulgação dos produtos e aumento nas vendas, além de evitar conflitos entre os membros.

Mueller, Schmidt e Kuerbis (2013) analisaram na governança em rede a segurança nas relações internacionais realizada com a utilização da internet. Nesse caso, os autores destacaram que mesmo havendo fortes atritos entre instituições ligadas ao 
poder público, houve contribuições trazidas pela governança para as redes, como: maior diálogo entre as organizações e segurança nas informações prestadas entre as instituições participantes da rede sem a necessidade do estabelecimento prévio de processos de troca de informações pela internet.

Figueiredo Filho (2015), por exemplo, apresentou as contribuições das estruturas de governança, cooperação e legitimidade para a construção do desenvolvimento regional sustentável no interior de São Paulo. O resultado da pesquisa mostrou que, apesar das dificuldades encontradas na estruturação da governança, elas tiveram a função de facilitar a construção de acordos entre atores sociais que defendiam interesses distintos.

Pode-se apresentar como conclusões sobre a apresentação das teorias, definições e benefícios gerados pela governança em redes de empresas que: não se chegou a um quadro teórico unitário que defina de forma específica um conceito sobre governança.

Outra consideração possível é que, apesar de evidentes os benefícios gerados pela governança a empresas agrupadas em redes, estes evidenciados nos estudos anteriormente apresentados, Lopes e Baldi (2009) chamam a atenção para o fato de que os estudos sobre governança de redes enfatizam aspectos estruturais e não processuais na análise de redes. Nesse caso, os estudos apenas caracterizam a governança, mas não buscam compreender como as características das organizações existentes em uma rede podem influenciar os benefícios gerados às empresas.

Na seção a seguir são expostos os procedimentos metodológicos adotados no estudo que contribuíram para a execução da pesquisa sobre a governança de uma rede de empresas para a consolidação da produção de biocombustíveis em Sergipe.

\section{METODOLOGIA}

Este estudo é qualitativo, pois é fundamentalmente interpretativo, já que se buscou o reconhecimento básico dos processos interpretativos e cognitivos inerentes à vida social, e permite ao pesquisador ter uma visão holística do fenômeno (CRESWELL, 2002). Pode ser classificado como um estudo exploratório e descritivo.

O estudo é considerado exploratório, se pois buscou saber que tipo de governança se estabeleceu na Rede Biodiesel Sergipe e que benefícios foram gerados para as organizações participantes. O estudo também é considerado descritivo, pois caracterizou as instituições participantes da Rede Biodiesel Sergipe e estabeleceu uma relação entre as características das empresas e como esses fatores influenciaram nos benefícios gerados às organizações participantes da Rede. 
A pesquisa em questão é considerada de corte transversal, pois as informações foram coletadas em um único momento com os representantes das instituições participantes da Rede. Segundo Neuman (1997), as pesquisas de corte transversal podem ser exploratórias, descritivas e explanatórias, mas são mais consistentes com a abordagem descritiva.

O tipo de estudo usado foi o estudo de caso único em que se considera a análise de um fenômeno contemporâneo e que, também, representa-se um caso extremo e revelador (YIN, 2010). O caso analisado foi o da Rede Biodiesel Sergipe, a única rede no Estado que realizou ações para a estruturação da produção de matéria-prima para o biodiesel em Sergipe e na qual foi observada a existência de governança.

A coleta das evidências ocorreu por meio de entrevistas semiestruturadas que, de acordo com Yin (2010), são um dos principais métodos de coleta de informações em um estudo de caso. Saunders, Lewis e Thornill (2007) destacam que as entrevistas semiestruturadas podem ser usadas para explorar e explicar temas que surgiram a partir do uso de um questionário.

Foram entrevistados os representantes das instituições que participavam das ações coletivas com as demais organizações da rede. O contato com os representantes das instituições participantes da Rede Biodiesel Sergipe foi realizado por meio de listas de presença utilizadas em encontros realizados entre os participantes da rede no Sergipetec. Do total de 12 empresas participantes, foram realizadas as entrevistas com quatro representantes, entre eles: Sergipe Parque Tecnológico (Sergipetec) (Presidente da Instituição); Banco do Brasil (técnico designado pela Instituição para participar das reuniões da Rede); Universidade Federal de Sergipe (pesquisador que participou das reuniões da Rede); Cooperativa de Produção, Comercialização e Prestação de Serviços dos Agricultores Familiares de Indiaroba e Região (Cooperafir) (ex-Presidente da organização).

As categorias analíticas do estudo foram definidas a partir dos objetivos e da revisão teórica sobre o tema. No Quadro 2, podem-se observar os objetivos específicos, as categorias que foram utilizadas, com os respectivos elementos de análise. 
Quadro 2 - Objetivos específicos, categorias analíticas e elementos de análise

\begin{tabular}{|c|c|c|}
\hline OBJETIVOS ESPECÍFICOS & CATEGORIAS & ELEMENTOS DE ANÁLISE \\
\hline \multirow{5}{*}{$\begin{array}{l}\text { Caracterizar o perfil dos par- } \\
\text { ticipantes da Rede Biodiesel } \\
\text { Sergipe. }\end{array}$} & \multirow{5}{*}{$\begin{array}{l}\text { Características das organizações } \\
\text { participantes da Rede (SEBRAE, } \\
\text { 2011; BRASIL, 2005). }\end{array}$} & Nome da instituição \\
\hline & & Tempo no mercado \\
\hline & & Número de funcionários \\
\hline & & Localização \\
\hline & & Tipo de sociedade \\
\hline \multirow{8}{*}{$\begin{array}{l}\text { Analisar se a governança da } \\
\text { Rede gerou benefícios às } \\
\text { organizações participantes. }\end{array}$} & \multirow{8}{*}{$\begin{array}{l}\text { Benefícios gerados pela gover- } \\
\text { nança } \\
\text { (RODRIGUES; MALO, 2006; } \\
\text { HUMPHREY; SCHMITZ, 2001; } \\
\text { CRUZ; MARTINS; QUANDT, } \\
\text { 2008; FITTIPALDI; DONAIRE, } \\
\text { 2009). }\end{array}$} & Acesso ao mercado \\
\hline & & $\begin{array}{l}\text { Aquisição de capacidades de } \\
\text { produção }\end{array}$ \\
\hline & & Acesso à assistência técnica \\
\hline & & Redução de custos \\
\hline & & Melhora na gestão \\
\hline & & Perpetuação do negócio \\
\hline & & Alto grau de especialização \\
\hline & & $\begin{array}{l}\text { Maior divulgação dos produtos } \\
\text { e aumento nas vendas }\end{array}$ \\
\hline
\end{tabular}

Fonte: os autores.

Segundo Yin (2010), para a validação dos dados em um projeto de pesquisa, é necessário que ele preveja resultados semelhantes (replicação literal), ou produza resultados contrastantes apenas por razões previsíveis (replicação teórica). De acordo com o autor, a validade de uma pesquisa pode ser de constructo, interna e externa.

A validade de constructo foi realizada por meio da utilização de múltiplas fontes de evidência, como: documentos da Rede para a escolha dos representantes a serem entrevistados, publicações de estudos realizados que mostraram o processo de formação da Rede Biodiesel Sergipe, além da comparação entre os resultados obtidos mediante as entrevistas realizadas com os representantes das subunidades de análise e os resultados obtidos por meio da entrevista com o representante da instituição que exerce a governança da Rede.

Já a validade externa ocorreu por meio da comparação dos resultados da pesquisa com o referencial teórico utilizado e da apresentação de evidências de como as características das instituições influenciaram quanto aos benefícios adquiridos pelas instituições. Dessa forma, a pesquisa serve como base teórica para estudos futuros sobre o tema abordado. 
Yin (2010) diz que para a confiabilidade das informações em uma pesquisa há a necessidade de se desenvolver um banco de dados. Assim, para garantir a segurança das informações, foi realizada a gravação das entrevistas, o que permitiu o registro preciso e imparcial da informação, além de possibilitar que outros pesquisadores possam utilizar as informações armazenadas (YIN, 2010). Após a transcrição das entrevistas, elas foram repassadas para os entrevistados, que validaram as informações prestadas.

\section{ANÁLISE DO CASO: A REDE BIODIESEL SERGIPE}

A Rede Biodiesel Sergipe é formada por diversos agentes e instituições públicas e privadas, entre elas a Secretarias de Estado do Desenvolvimento Econômico da Ciência e Tecnológica (Sedetec), a Secretaria de Estado do Planejamento (Seplan) e a Secretaria de Agricultura (Seagri); entidades de pesquisa como Embrapa Tabuleiros Costeiros; representantes dos agricultores e agricultoras (Federação dos Trabalhadores na Agricultura de Sergipe (Fetase); movimentos sociais (Movimento dos Trabalhadores Sem Terra (MST) e cooperativas de agricultura familiar e Petrobras (Unidade Sergipe-Alagoas (UN/SEAL) e, posteriormente, Petrobras Biocombustível, a partir de 2009).

A partir de 2007, os grupos que passaram a se reunir semanalmente no Sergipetec, se assumiram como Rede Biodiesel Sergipe em virtude da necessidade de manutenção das discussões e da elaboração de um planejamento a ser proposto e enviado ao Governo estadual e, também, em razão da ausência de um programa de biodiesel institucionalizado em Sergipe.

Assim, a Rede Sergipe Biodiesel assume um papel diferenciado que inclui levantar e organizar as demandas dos potenciais produtores rurais, de suas organizações profissionais e da indústria para a ciência e, ao mesmo tempo, buscando nas pesquisas e suas entidades propostas de melhorias e viabilização de inovações tecnológicas e sócio-organizacionais para a produção de biodiesel. É importante destacar que a produção agrícola em Sergipe era um segmento que se encontrava desorganizado e com fortes necessidades de aprendizagem, que precisava ser desenvolvido para atender aos termos contratuais exigidos pela indústria de biodiesel (VITAL BRAZIL et al., 2009).

Portanto, a dinâmica da Rede Biodiesel Sergipe foi fortalecida com a negociação das cooperativas de agricultores e a Petrobras para o fornecimento de grãos e, posteriormente, o serviço de assistência técnica e capacitação, e, assim, o desenho da Rede foi completado em torno de quatro polos centrais, nos quais cada participante 
tinha suas ações definidas e tendo o Sergipetec como mediador. Na Figura 1 é possível visualizar a estrutura da Rede Biodiesel Sergipe.

Figura 1 - Estrutura da Rede Biodiesel Sergipe.

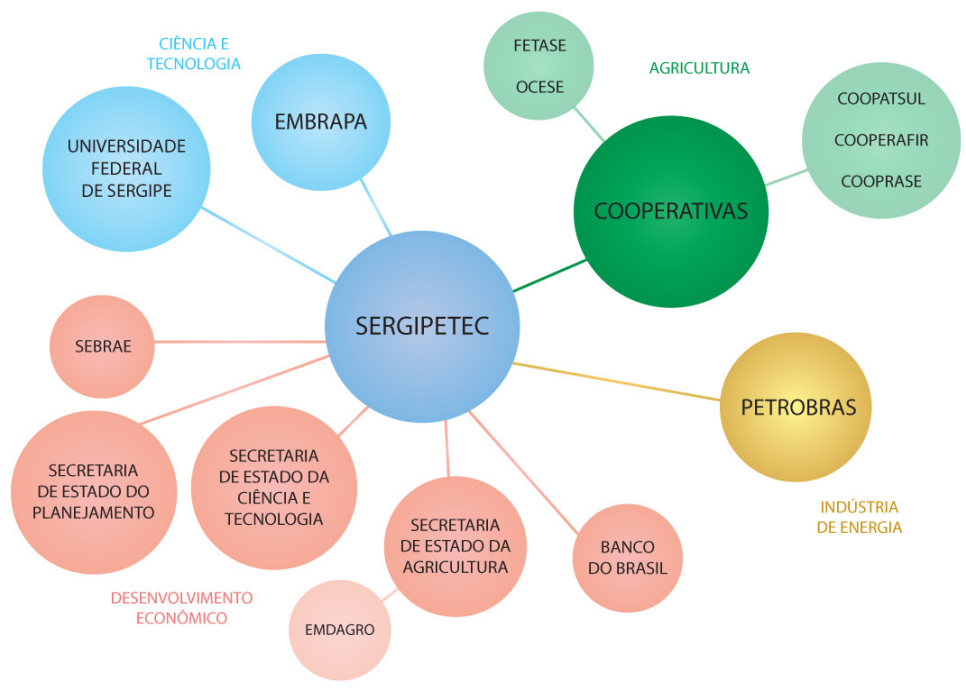

Fonte: os autores.

As organizações participantes da Rede ligadas à ciência e tecnologia têm a função de desenvolver estudos e pesquisas para a evolução da cadeia produtiva do biodiesel. A Universidade Federal de Sergipe (UFS) trabalha na parte de pesquisas ligadas ao aproveitamento de resíduos e tipos de sementes oleaginosas para a produção do biodiesel. Já a Embrapa Tabuleiros Costeiros possui a função do desenvolvimento de pesquisas na área agrícola, com a finalidade de contribuir com o aumento da produção de oleaginosas, especificamente a do girassol, que foi a semente indicada pela Embrapa para ser produzida em Sergipe com a finalidade de produzir óleo para o biodiesel.

As funções da indústria de energia na Rede Biodiesel Sergipe são as de comprar a produção de oleaginosas dos agricultores familiares e contratar uma instituição que forneça assistência técnica para os agricultores produtores de oleaginosas. Essa assistência técnica trata da orientação dos agricultores familiares em relação a melhores práticas de produzir oleaginosas para contribuir com o aumento da produção. É importante destacar que as duas funções da indústria de energia destacadas são 
obrigatórias por lei, destacadas na Instrução Normativa do Ministério do Desenvolvimento Agrário (MDA) 01 de 2009 (BRASIL, 2009).

As instituições ligadas à área de desenvolvimento econômico possuem a função de oferecer condições às organizações representantes da agricultura para produzirem oleaginosas e terem acesso ao crédito bancário para a produção agrícola.

A agricultura familiar tem a função de representar os produtores rurais na negociação com a indústria de energia. As cooperativas são as instituições que possuem a função de negociar diretamente os contratos de compra da produção agrícola. Já a Federação dos Agricultores Agrícolas de Sergipe (Fetase) e a Organização das Cooperativas de Sergipe (Ocese) têm como função a negociação dos preços das sementes produzidas pelos agricultores familiares.

As instituições participantes da Rede Biodiesel Sergipe escolhidas para a pesquisa foram: o Banco do Brasil, a Universidade Federal de Sergipe, a cooperativa agrícola Cooperafir e o Sergipe Parque Tecnológico. Os relatos dos representantes das organizações em questão foram organizados nessa ordem. Para a melhor visualização das respostas apresentadas pelos representantes institucionais, foi incluído um quadro/resumo no final de cada entrevista.

\subsection{INSTITUIÇÃO 1: O CASO DO BANCO DO BRASIL}

O Banco do Brasil S/A é uma instituição financeira denominada sociedade de economia mista, fundada em 12 de outubro de 1808 na cidade do Rio de Janeiro. A sede de Aracaju do Banco do Brasil está localizada na Praça General Valadão, no centro da cidade, e possui cerca de 400 funcionários em sua sede. Na sede do Banco em Sergipe são oferecidos aos clientes atendimento eletrônico e físico de caixa, financiamentos, empréstimos, consórcios, seguros e previdência privada, entre outros.

O Banco do Brasil de Sergipe, entre as suas principais atividades, possui em sua estrutura uma superintendência denominada Desenvolvimento Regional Sustentável (DRS), localizada no sexto andar do prédio do Banco. O DRS do Banco do Brasil é uma estratégia de negócios que busca impulsionar o desenvolvimento sustentável das regiões onde o Banco do Brasil está presente. Entre as atividades desenvolvidas, a superintendência de DRS tem por função o suporte ao produtor rural com financiamento da produção agrícola e de projetos de suporte à agricultura familiar para a aquisição de sementes, insumos para a produção e financiamento de equipamentos agrícolas. 
Para fornecer informações sobre a participação do Banco do Brasil na Rede Biodiesel Sergipe, foi designado pelo Banco para ser entrevistado o senhor João Cezar Silva Fernandes, que é assessor em projetos de agronegócio e de responsabilidade socioambiental do Banco. É importante destacar que o senhor João Cezar foi o representante que fez toda a interlocução da relação do Banco com a Rede estudada.

O entrevistado destacou a contribuição da governança da Rede para a aquisição de capacidades de produção pelo número de pessoas interessadas na aquisição de matéria-prima para biodiesel. Nesse caso, houve a disponibilização de informações importantes que o Banco acessou para aumentar o número de clientes, conforme explicou:

\begin{abstract}
Imagine você que naquele momento houve um número grande de pessoas interessadas na produção de girassol, que é umas das matérias-primas para o biodiesel, e foi nos passado uma relação de mais de três mil agricultores. Isso aí foi um banco de dados para trazer mais gente para ser cliente do Banco. Isso foi grande! Muito importante pra gente. Não só na produção de girassol como para qualquer tipo de produção. (informação verbal).
\end{abstract}

Outro fator destacado pelo entrevistado foi a possibilidade de as instituições reduzirem os seus custos por meio do acesso a serviços oferecidos pelas outras instituições participantes da Rede. Nesse caso, foi informado que algumas instituições ofereciam cursos e capacitações gratuitos e que outros parceiros somente tinham acesso a partir da contratação do serviço, conforme relatou:

Reduz porque a partir do momento que se tem um parceiro para
realizar uma ação, a instituição que necessitava de algo não pre-
cisava contratar o serviço. Isso reduz o custo para a instituição.
Quando a instituição que exercia a governança identificava a
necessidade de alguma instituição, automaticamente, entrava-
-se em contato com os parceiros que identificavam quem pode-
ria oferecer o serviço. (informação verbal).

Já em relação ao planejamento do processo de produção de matéria-prima para o biodiesel, o entrevistado relatou que a governança da Rede foi de suma importância para determinar e deixar claro entre as instituições qual era o papel de cada organização na cadeia de produção de matéria-prima para o biodiesel.

Apesar de a governança ser importante para a gestão das organizações participantes da Rede, o entrevistado destacou que sua organização não apresentou melhorias em sua gestão. Nesse caso, o Banco do Brasil, por ser uma instituição pública e 
consolidada, não teria a necessidade de executar mudanças na sua gestão para oferecer seus serviços às instituições participantes da Rede. Pelo mesmo fato, o entrevistado informou que a governança da Rede não influenciou a perpetuação das atividades do Banco do Brasil. Porém, destacou que a governança foi de extrema importância para a elevação do grau de especialização de organizações, principalmente as ligadas à agricultura familiar.

No Quadro 3, é possível visualizar resumidamente as categorias analíticas utilizadas no estudo.

Quadro 3 - Resumo dos resultados da pesquisa na Instituição 1

\begin{tabular}{|c|c|c|}
\hline CATEGORIAS & ELEMENTOS DE ANÁLISE & RESULTADOS ALCANÇADOS \\
\hline \multirow{5}{*}{$\begin{array}{l}\text { Caracterização das or- } \\
\text { ganizações participantes } \\
\text { da Rede }\end{array}$} & Nome da instituição & Banco do Brasil S/A \\
\hline & Tempo no mercado & 205 anos \\
\hline & Número de funcionários & 400 \\
\hline & Localização & $\begin{array}{l}\text { Praça General Valadão - Centro - } \\
\text { Aracaju }\end{array}$ \\
\hline & Tipo de sociedade & Sociedade de Economia Mista \\
\hline \multirow{8}{*}{$\begin{array}{l}\text { Benefícios gerados pela } \\
\text { governança }\end{array}$} & Acesso ao mercado & Sim. Entrada de novos clientes. \\
\hline & $\begin{array}{l}\text { Aquisição de capacidades de } \\
\text { produção }\end{array}$ & $\begin{array}{l}\text { Sim. Elevação da capacidade de } \\
\text { oferta de produtos e serviços. }\end{array}$ \\
\hline & Acesso à assistência técnica & Sim. Acesso a capacitações. \\
\hline & Redução de custos & $\begin{array}{l}\text { Sim. Distribuição de custos com } \\
\text { serviços realizados. }\end{array}$ \\
\hline & Melhoria na gestão & $\begin{array}{l}\text { Não. A instituição tinha seus proces- } \\
\text { sos bem definidos. }\end{array}$ \\
\hline & Perpetuação do negócio & $\begin{array}{l}\text { Não. A instituição já estava bem } \\
\text { consolidada no seu negócio. }\end{array}$ \\
\hline & Alto grau de especialização & $\begin{array}{l}\text { Sim. Importante para a especializa- } \\
\text { ção de algumas instituições. }\end{array}$ \\
\hline & $\begin{array}{l}\text { Maior divulgação dos produtos } \\
\text { e aumento nas vendas }\end{array}$ & $\begin{array}{l}\text { Sim. Oportunidade de divulgar seus } \\
\text { produtos. }\end{array}$ \\
\hline
\end{tabular}

Fonte: os autores. 


\subsection{INSTITUIÇÃO 2: A UNIVERSIDADE FEDERAL DE SERGIPE}

A Universidade Federal de Sergipe foi criada em 15 de maio de 1968, por meio do Decreto-Lei n. 269. Possui cinco Campi de ensino presencial nos Municípios de São Cristóvão, Aracaju, Itabaiana, Laranjeiras e Lagarto e 14 polos de Educação a Distância nos Municípios de Arauá, Brejo Grande, Estância, Japaratuba, Laranjeiras, Lagarto, Poço Verde, Porto da Folha, São Domingos, Carira, Nossa Senhora das Dores, Nossa Senhora da Glória, Propriá e São Cristóvão.

Para contribuir com informações sobre a participação da Universidade Federal de Sergipe na Rede Biodiesel Sergipe, foi realizado o contato com o Professor Doutor Gabriel Francisco da Silva, coordenador responsável pelo Laboratório de Tecnologia de Alimentos (LTA) da referida Universidade. O entrevistado é o representante principal na relação entre a Universidade e a Rede Biodiesel Sergipe a respeito das pesquisas sobre a produção de biodiesel.

Uma das consequências existentes da colaboração entre as instituições participantes da Rede Biodiesel Sergipe, com o apoio da governança, foi o acesso a novos mercados pelas instituições. Nesse caso, o entrevistado destacou que a governança contribuiu para o acesso a projetos e grupos de pesquisa além da produção de biodiesel:

Tivemos projetos na área de fruticultura, cadeia produtiva do leite, o próprio projeto biodiesel. Todos eles trouxeram bolsas e oportunidades de pesquisas para os alunos. Foram formados grupos de pesquisa e isso contribuiu com os projetos desenvolvidos aqui na Universidade. Temos um projeto na área de energias renováveis diretamente com o Sergipetec. (informação verbal).

O entrevistado enalteceu a questão da pesquisa quando questionado se a governança da Rede contribuiu com a aquisição de capacidade de produção. Nesse caso, foi destacado que houve um aumento de pesquisas na área de biocombustíveis:

\footnotetext{
Tem a questão da pesquisa. É claro que o professor tem um currículo que ajuda. Mas se você tem um projeto que quer realizar e tem como referência a realização de outro, facilita você conseguir o recurso. Isso repercute nos cursos de graduação, nas pesquisas, porque a Instituição oferece projetos para os alunos estudarem. (informação verbal).
}

Outra contribuição da governança da Rede Biodiesel Sergipe foi o acesso a iniciativas de capacitação. Foi destacada pelo entrevistado a elevação no número de pesquisadores e alunos interessados e executarem pesquisas na área de biocombustíveis: 
Sim. Porque outras pessoas contribuíram para a melhoria de formação de recursos humanos. Houve um aumento de mão de obra capacitada para o Estado. Nossos alunos e nossos bolsistas participam de programas de capacitação. Atraiu alunos para o Estado. Atraiu por conta da Rede. (informação verbal).

Apesar das contribuições relacionadas à formação de mão de obra que a governança da Rede Biodiesel Sergipe proporcionou, o entrevistado relatou que a redução de custos para as organizações participantes foi relativa:

Creio que seja relativo. Hoje nós temos uma estrutura para oferta de vários serviços. Se nós temos uma estrutura maior, a tendência é que os custos sejam mais elevados por um lado. Por outro lado, um determinado serviço que nós teríamos que contratar por conta da falta de estrutura, nós fazemos internamente. Então creio que seja relativo. (informação verbal).

O entrevistado destacou que não existem contribuições da governança para a redução de custos. Também não houve impactos na gestão da Universidade Federal de Sergipe pelo fato de ela já possuir um modelo de gestão consolidado:

\begin{abstract}
A Universidade tem seu jeito de gestão. As interferências são pequenas. Mas acredito que em outras instituições sim. A Embrapa, por exemplo, realizou várias pesquisas. Creio que foi muito importante para as cooperativas. A Universidade já possui sua forma de gerir. (informação verbal).
\end{abstract}

A perpetuação da atividade da sua organização foi outra ação que, segundo o entrevistado, não teve influência da governança da Rede. Nesse caso, a perpetuação na atividade de pesquisa pela Universidade Federal tratou-se de uma evolução natural de difícil associação à influência da governança da Rede:

Creio que as mudanças foram muito naturais. É difícil de dimensionar esse processo. Vieram várias pessoas de fora trabalhar na Universidade na área de biocombustíveis, mas não acredito que foi por conta da governança da rede. Creio que foi um processo natural de crescimento. (informação verbal).

Em outro ponto, o entrevistado destacou que houve uma grande influência da governança da Rede Biodiesel Sergipe para o maior grau de especialização da Uni- 
versidade Federal. Destacou-se que houve uma evolução no número de estudantes e pesquisadores, conforme relatou:

Hoje eu tenho vários alunos que estão fazendo mestrado, doutorado e que são professores. Muitos alunos trabalharam na área de extração e produção de biodiesel, tratamento de água em suas pesquisas. A gente tem várias pessoas que tiveram bolsas e realizam estudos nessa área. Esse processo gerou várias oportunidades de bolsas e pesquisas em biodiesel. (informação verbal).

Apesar do número de pesquisadores e da oportunidade que os alunos da Universidade Federal tiveram de realizar estudos e de captação de projetos, o entrevistado não atribuiu à governança da Rede influência na maior divulgação dos serviços oferecidos pela Universidade.

Com a finalidade de simplificar a visualização das respostas apresentadas pelo entrevistado representante da Universidade Federal de Sergipe, no Quadro 4 é possível visualizar um resumo dos conteúdos abordados na entrevista.

Quadro 4 - Resumo dos resultados da pesquisa na Instituição 2

\begin{tabular}{|c|c|c|}
\hline CATEGORIAS & ELEMENTOS DE ANÁLISE & RESULTADOS \\
\hline \multirow{5}{*}{$\begin{array}{l}\text { Caracterização das or- } \\
\text { ganizações participantes } \\
\text { da Rede }\end{array}$} & Nome da instituição & Universidade Federal de Sergipe \\
\hline & Tempo no mercado & 46 anos \\
\hline & Número de funcionários & 2.578 funcionários \\
\hline & Localização & Sede em São Cristóvão - Sergipe \\
\hline & Tipo de sociedade & Autarquia Federal \\
\hline \multirow{8}{*}{$\begin{array}{l}\text { Benefícios gerados pela } \\
\text { governança }\end{array}$} & Acesso ao mercado & Sim. Novos projetos. \\
\hline & $\begin{array}{l}\text { Aquisição de capacidades de } \\
\text { produção }\end{array}$ & Sim. Aumento das pesquisas. \\
\hline & Acesso à assistência técnica & Sim. Aumento de mão de obra capacitada. \\
\hline & Redução de custos & Não. \\
\hline & Melhoria na gestão & $\begin{array}{l}\text { Não. A organização possui sua forma } \\
\text { de gerir bem definida. }\end{array}$ \\
\hline & Perpetuação do negócio & Não. \\
\hline & Alto grau de especialização & $\begin{array}{l}\text { Sim. Alunos bolsistas, de mestrado, } \\
\text { doutorado e professores. }\end{array}$ \\
\hline & $\begin{array}{l}\text { Maior divulgação dos produtos } \\
\text { e aumento nas vendas }\end{array}$ & Não. \\
\hline
\end{tabular}

Fonte: os autores. 


\subsection{INSTITUIÇÃO 3: A COOPERAFIR}

A Cooperativa de Produção, Comercialização e Prestação de Serviços dos Agricultores Familiares de Indiaroba e Região (Cooperafir) é um órgão associativo de pessoas com formas e características jurídicas próprias, constituídas sob a égide da legislação cooperativista vigente. Composta por trabalhadores rurais, pequenos agricultores e agricultores familiares, a organização possui 739 cooperados e sete funcionários responsáveis pela gestão. A cooperativa foi fundada no dia 16 de setembro de 2007 e localiza-se no Assentamento Sete Brejos, S/N, na Zona Rural do Município de Indiaroba, Sergipe.

A cooperativa comercializa a produção de grãos de girassol, além do beneficiamento e processamento dos produtos dos cooperados, para agregar valor. A organização também produz leite de coco com a marca Cooperafir, comercializa macaxeira descascada e embalada a vácuo e polpa de frutas congelada.

Como consequência da influência da governança nas instituições participantes da Rede Biodiesel Sergipe, o entrevistado destacou o fato de a cooperativa acessar novos mercados. Assim, foi relatado que a atuação da governança possibilitou implantar estruturas de beneficiamento de frutas e atuar em mercados ainda novos para a Instituição:

Sem dúvida. A gente se qualificou nesse processo. Estamos longe do ideal, mas acredito que em cinco anos, nós avançamos vinte anos. Conseguimos sede própria, unidade de beneficiamento de macaxeira embalada a vácuo, capacitação da juventude camponesa [...] a gente não tinha nada disso antes. De equipamentos, de contratos com a Petrobras, de contrato com o BNDES, o próprio PNPB. (informação verbal).

Além de acessar novos mercados, as contribuições foram evidentes quanto à aquisição de capacidade de produção. Nesse caso, a cooperativa conseguiu desenvolver seus processos produtivos e aumentar a produção de seus cooperados, conforme relatou:

\footnotetext{
A gente tem um ganho real disso, principalmente em outras possibilidades. Nós diversificamos. Sempre existiu um pensamento de que o agricultor que crescia só poderia produzir uma cultura, mas hoje o pensamento é outro, é a diversificação. Então houve a diversificação. Plantamos o girassol consorciado com a laran-
} 
ja. A produção aumentou e o controle de pragas foi importante. E a laranja também produziu mais. (informação verbal).

A governança da Rede também proporcionou à cooperativa a oportunidade de ter acesso a iniciativas de capacitação e assistência técnica. Dessa forma, o entrevistado destacou que ações de capacitação em gestão e em processos de produção agrícola foram primordiais para o desenvolvimento da Instituição:

Nós tivemos com o Sebrae, inicialmente, uma capacitação na área de gestão e, atualmente, com relação ao layout dos produtos produzidos pela cooperativa. Nós tivemos com o CVT do Sergipetec a capacitação de mais de 600 jovens de base familiar ligada à agricultura ou de colônias de pescadores [...] não tínhamos acesso à tecnologia, mas quando acessamos não tínhamos o conhecimento de como utilizar essa tecnologia. A Embrapa nos ajudou nisso. Esse acesso contínuo à capacitação mudou nossa realidade. Isso faz com que o campo seja visto como um ótimo lugar para se morar. (informação verbal).

Uma das consequências das ações de planejamento da produção agrícola e do acesso a capacitações foi a redução de custos em várias ações da Cooperativa. Segundo o entrevistado, a redução de custos ocorreu como consequência das orientações que a Organização teve por parte da governança para a eliminação de erros nos processos de planejamento:

\begin{abstract}
Sim, ela foi estratégica [...] na área de máquinas, reduzimos a depreciação dos equipamentos e o gasto com combustível. O planejamento da produção foi importantíssimo, porque a agricultura não admite erros, e a resposta a um erro deve ser imediato. Pode-se perder uma safra toda. E houve uma disciplina para que os erros fossem evitados. (informação verbal).
\end{abstract}

A organização do processo produtivo também contribuiu para a melhoria da gestão da Cooperativa. Como foi dito pelo entrevistado, a organização de processos e o planejamento das atividades serviram de apoio para a melhoria da gestão, conforme relatou:

Foi fundamental, porque a relação da gestão, cada vez mais se exige de capacitação. Mas a gente não vai deixar de ser agricultor para ser contador. Ou deixar de ser agricultor para ser advogado. Mas nós temos a consciência, hoje, que é muito difícil alguém nos enganar. Colocamos as pessoas corretas nos lugares 
corretos. Nunca deixamos de ter uma certidão em dia, o que era impensável no começo da cooperativa. O balanço contábil, os contratos, definição de custos fixos e variáveis, foi importante.

Uma das consequências principais das atividades de planejamento e da melhoria da gestão foi a contribuição para a perpetuação da Cooperativa. Segundo o entrevistado, as cooperativas agrícolas sofrem com a falta de planejamento, e, consequentemente, isso pode influenciar a manutenção da atividade. Com o apoio da governança da Rede Biodiesel Sergipe, a Cooperativa teve a oportunidade de adquirir novas parcerias que auxiliaram a preservação das atividades da Organização, conforme destacou:

Deu perenidade. A gente entende que atuamos com pessoas e os resultados são em longo prazo. Nós somos um movimento de resistência ao sistema, mas temos a consciência que para a nossa sobrevivência temos que ter contratos e ter relação com instituições governamentais. Essa postura deu perenidade à nossa sobrevivência [...] é muito difícil uma cooperativa chegar aos cinco anos, e estamos nos aproximando dos dez. A governança fez com que a gente teve a consciência da cooperação, da responsabilidade, da disciplina. (informação verbal).

Para a melhor visualização dos resultados da entrevista com o representante da Cooperafir, no Quadro 5 se encontra um resumo das respostas apresentadas pelo entrevistado. 
Quadro 5 - Resumo dos resultados da pesquisa na Instituição 3

\begin{tabular}{|c|c|c|}
\hline CATEGORIAS & ELEMENTOS DE ANÁLISE & RESULTADOS \\
\hline \multirow{5}{*}{$\begin{array}{l}\text { Caracterização das } \\
\text { organizações partici- } \\
\text { pantes da rede }\end{array}$} & Nome da instituição & $\begin{array}{l}\text { Cooperativa de Produção, Comercia- } \\
\text { lização e Prestação de Serviços dos } \\
\text { Agricultores Familiares de Indiaroba } \\
\text { e Região Cooperafir }\end{array}$ \\
\hline & Tempo no mercado & 6 anos \\
\hline & Número de funcionários & 739 \\
\hline & Localização & Indiaroba - Sergipe \\
\hline & Tipo de sociedade & Cooperativa \\
\hline \multirow{7}{*}{$\begin{array}{l}\text { Benefícios gerados } \\
\text { pela governança }\end{array}$} & Acesso ao mercado & $\begin{array}{l}\text { Sim. A governança possibilitou o } \\
\text { acesso a novos mercados para as } \\
\text { Cooperativa. }\end{array}$ \\
\hline & $\begin{array}{l}\text { Aquisição de capacidades de } \\
\text { produção }\end{array}$ & $\begin{array}{l}\text { Sim. A governança contribuiu para } \\
\text { a diversificação de processos de } \\
\text { produção. }\end{array}$ \\
\hline & Redução de custos & $\begin{array}{l}\text { Sim. A governança contribuiu com } \\
\text { o planejamento, e o este ajudou a } \\
\text { Cooperativa a reduzir custos. }\end{array}$ \\
\hline & Melhoria na gestão & $\begin{array}{l}\text { Sim. A governança contribuiu para } \\
\text { que a Cooperativa tivesse mais aten- } \\
\text { ção à gestão da organização. }\end{array}$ \\
\hline & Perpetuação do negócio & $\begin{array}{l}\text { Sim. A governança contribuiu para a } \\
\text { longevidade da Cooperativa. }\end{array}$ \\
\hline & Alto grau de especialização & $\begin{array}{l}\text { Sim. A governança ofereceu con- } \\
\text { dições para que as Organização se } \\
\text { tornasse mais especializada. }\end{array}$ \\
\hline & $\begin{array}{l}\text { Maior divulgação dos produtos e } \\
\text { aumento nas vendas }\end{array}$ & $\begin{array}{l}\text { Sim. A governança contribuiu para } \\
\text { que a Cooperativa oferecesse produ- } \\
\text { tos para novas instituições. }\end{array}$ \\
\hline
\end{tabular}

Fonte: os autores.

\subsection{INSTITUIÇÃO 4: O SERGIPETEC}

Fundada no ano 2003 e com o início das suas atividades em 2004, o Sergipe Parque Tecnológico Sergipetec é uma associação privada, sem fins lucrativos, reconhecida como Organização Social Estadual. Para a consecução das suas atividades, o Sergipetec conta com 104 funcionários. Até 2014, a Instituição abrigava mais de 21 empresas, três incubadoras de empresas e seis instituições de pesquisa.

O Sergipetec atua no fomento à criação de empresas de base tecnológica e à construção de redes de relacionamentos que envolvam agentes do processo produtivo, da geração, do conhecimento, do ensino, da pesquisa e da inovação. Para realizar as ações expostas, o parque tecnológico atua em conjunto com a Secretaria Estadual do 
Desenvolvimento Econômico, da Ciência, Tecnologia e Inovação Sedetec, fazendo parte do sistema de inovação do Estado.

Até o início de 2014, o Sergipetec estava instalado em prédio cedido pela Federação das Indústrias, localizado no bairro Capucho, em Aracaju. A sede definitiva do Sergipetec foi construída em uma área de mais de $130.000 \mathrm{~m}^{2}$, contígua à Universidade Federal de Sergipe, em local que possibilita total integração entre o ambiente acadêmico, o mercado e o Estado.

A pessoa escolhida para participar desta pesquisa foi o senhor Marcos Wandir Nery Lobão, Diretor-Presidente do Sergipetec desde 2009. O entrevistado assumiu o cargo já com as ações da Rede Biodiesel Sergipe em andamento. Dessa forma, pode dar informações precisas sobre o surgimento da Rede, pois participou da sua estruturação.

Uma das consequências das relações estabelecidas entre as organizações participantes da Rede Biodiesel Sergipe foi o acesso a novos mercados. Nesse caso, o entrevistado destacou vários ganhos obtidos pelas cooperativas de agricultores familiares, como: garantia de compra da produção, acesso a crédito bancário, acesso a sementes de qualidade e zoneamento agrícola da cultura do girassol em todo o Estado:

\begin{abstract}
Na minha maneira de ver vou citar dois exemplos: para o homem do campo, trouxe condições para que sua produção tivesse garantia de compra e investimentos para o seu crescimento. Foi criado um mercado. Não adianta produzir sem ter pra quem vender. O ponto forte também foi oferecer qualidade de sementes, orientação para esse agricultor e principalmente o zoneamento de Sergipe para o plantio de girassol. Existiam apenas dois municípios zoneados, como não se tem crédito bancário sem zoneamento agrícola. Creio que nesse aspecto a atuação do Sergipetec foi fundamental. (informação verbal).
\end{abstract}

É importante destacar que o zoneamento agrícola trata-se de um documento que autoriza o plantio de uma cultura alimentícia no Estado. Esse documento é de extrema importância, pois além de garantir condições sanitárias para o plantio, possibilita que o pequeno produtor tenha acesso a crédito bancário. Nesse caso, quem articulou o zoneamento agrícola do girassol para Sergipe foi o Sergipetec, em parceria com a Embrapa e a Empresa de Desenvolvimento Agropecuário de Sergipe (Emdagro).

Além de destacar o acesso a novos mercados pelas cooperativas agrícolas, a governança da Rede contribuiu para que os agricultores familiares tivessem a oportunidade de receber sementes de qualidade para o plantio de oleaginosas. Também foi relatado que as instituições acadêmicas tiveram a oportunidade de aumentar sua capa- 
cidade de produção de pesquisas. Assim, houve a formação de grupos de pesquisas, a produção de artigos científicos e o acesso a projetos na área de biodiesel. Dessa forma, nos dois casos teve o aumento da capacidade de produção, conforme destacado:

Do ponto de vista acadêmico, o Sergipetec induziu a existência de pesquisas nessa área. As pessoas começaram a trabalhar mais em grupo. Antes era muito individual. O caráter indutor é do Sergipetec. Houve uma organização da área de pesquisa. Do ponto de vista do campo, eu destaco as sementes de girassol. Antes da Rede, houve um experimento com sementes velhas, que deu resultados ruins. Depois da Rede, com parceria da Embrapa, as sementes eram novas e experimentadas no campo. Houve a transferência dessa tecnologia para o campo. Houve também a formação de multiplicadores. (informação verbal).

Foi dado maior destaque pelo entrevistado ao acesso do produtor rural de Sergipe ao aprendizado de uma nova cultura, à renda e a uma política de distribuição de sementes de qualidade, conforme relembrou:

Eu posso fazer uma síntese. Acho que é resultado concreto o aprendizado do nosso agricultor do manejo com essas oleaginosas. A produção aconteceu e se vende até hoje [...] a partir disso o agricultor conseguiu ter acesso à renda. Hoje se tem uma política de sementes, para o agricultor ter uma semente de qualidade. O conhecimento foi multiplicado. (informação verbal).

Como informado anteriormente pelo entrevistado, os agricultores familiares cooperados tiveram acesso à capacitação e assistência técnica por meio da orientação da instituição governante da Rede, que ofereceu atividades de campo para os agricultores sobre o plantio de oleaginosas, o que resultou em vários benefícios. Nesse caso, o trabalho conjunto para a realização das atividades de transferência de tecnologia para o agricultor familiar gerou a redução de custos para as instituições, o que ocorreu por meio da divisão de despesas de cada capacitação oferecida aos agricultores, conforme destacou:

Na hora que você trabalha em rede você une esforços. Cada um dá o que tem. O somatório das partes foi importante para alcançar o todo. O Sergipetec ajudou nos dias de campo para orientar os agricultores sobre o plantio. Ele já fazia experimentos de campo, mas teve o suporte de outras instituições. Creio 
que se fossem ações isoladas o custo seria muito maior. Por isso acredito que o custo reduziu. (informação verbal).

Segundo o entrevistado, a ação de planejar melhorou a gestão em grupos de pesquisas, na formação de pessoas e elaboração de projetos, conforme relatou:

Eu diria que irradiou boas influências. Mas acho que em determinado momento teve uma sinergia. As boas metodologias de gestão irradiaram para as instituições. Começaram a falar em grupos de pesquisa, formação de pessoas, grupos produzindo projetos, participação em eventos. Contribuiu para dar organização às ações de todas as instituições. (informação verbal).

Apesar de a melhoria na gestão ser atribuída às instituições de pesquisa, o entrevistado considerou que a atuação da governança foi importante para a consolidação das instituições cooperativas que tiveram acesso a tecnologias para melhorar a produção agrícola, conforme destacou:

Olha, se você tem um olhar diferenciado para as cooperativas, vejo que sim. Para as demais instituições, creio que menos. São instituições já sólidas. Mas para o cooperativismo foi um baita de um exemplo que pode ser usado em outros casos. Houve a participação dos agricultores e mudou a realidade dessas instituições. A agricultura pedia tecnologia no campo. (informação verbal).

O entrevistado também destacou que a governança teve grande importância para as organizações cooperativas e para as instituições de ensino e pesquisa para que as pessoas atingissem um maior grau de especialização. Em outro ponto, a governança da Rede Biodiesel Sergipe foi importante para que as cooperativas de agricultura familiar tivessem a oportunidade de mostrar seus produtos e aumentar as vendas.

Para a melhor visualização dos resultados da entrevista com o representante da instituição governante da Rede Biodiesel Sergipe, no Quadro 6 se apresenta um resumo das respostas concedidas pelo entrevistado. 
Quadro 6 - Resumo dos resultados da pesquisa na Instituição 4

\begin{tabular}{|c|c|c|}
\hline CATEGORIAS & ELEMENTOS DE ANÁLISE & RESULTADOS \\
\hline \multirow{5}{*}{$\begin{array}{l}\text { Caracterização das or- } \\
\text { ganizações participantes } \\
\text { da Rede }\end{array}$} & Nome da instituição & $\begin{array}{l}\text { Sergipe Parque Tecnológico Ser- } \\
\text { gipetec }\end{array}$ \\
\hline & Tempo no mercado & 11 anos. \\
\hline & Número de funcionários & 104 funcionários \\
\hline & Localização & Aracaju, Sergipe \\
\hline & Tipo de Sociedade & Organização Social Estadual \\
\hline \multirow{8}{*}{$\begin{array}{l}\text { Benefícios gerados pela } \\
\text { governança }\end{array}$} & Acesso ao mercado & $\begin{array}{l}\text { A governança induziu a realização } \\
\text { de pesquisas e acesso a novos } \\
\text { mercados das cooperativas. }\end{array}$ \\
\hline & $\begin{array}{l}\text { Aquisição de capacidades de } \\
\text { produção }\end{array}$ & $\begin{array}{l}\text { A governança contribuiu para que } \\
\text { as instituições oferecessem novos } \\
\text { produtos. }\end{array}$ \\
\hline & Acesso à assistência técnica & $\begin{array}{l}\text { A governança ofereceu condições } \\
\text { para que as cooperativas acessas- } \\
\text { sem capacitações. }\end{array}$ \\
\hline & Redução de custos & $\begin{array}{l}\text { A governança articulou ações } \\
\text { conjuntas que reduziram os custos } \\
\text { das instituicões. }\end{array}$ \\
\hline & Melhoria na gestão & $\begin{array}{l}\text { Boas açôes aplicadas pela gover- } \\
\text { nança foram utilizadas pelas insti- } \\
\text { tuicões. }\end{array}$ \\
\hline & Perpetuação do negócio & $\begin{array}{l}\text { A governança contribuiu para que } \\
\text { as cooperativas consolidassem suas } \\
\text { atividades. }\end{array}$ \\
\hline & Alto grau de especialização & $\begin{array}{l}\text { A governança contribuiu para que as } \\
\text { instituições de pesquisa e as coopera- } \\
\text { tivas adquirissem especialidades. }\end{array}$ \\
\hline & $\begin{array}{l}\text { Maior divulgação dos produtos e } \\
\text { aumento nas vendas }\end{array}$ & $\begin{array}{l}\text { A governança contribuiu para que } \\
\text { as cooperativas aumentassem suas } \\
\text { vendas e os bancos disponibilizas- } \\
\text { sem crédito. }\end{array}$ \\
\hline
\end{tabular}

Fonte: os autores.

\section{RESULTADOS}

Em relação ao acesso ao mercado, dos quatro entrevistados, três representantes relataram que as cooperativas agrícolas foram as mais beneficiadas por meio da influência da instituição governante (Banco do Brasil, Cooperafir e Sergipetec). É importante destacar que uma das finalidades do PNPB é integrar agricultores familiares à cadeia produtiva de biodiesel. Entretanto, os representantes das demais Instituições 
informaram que os ganhos foram evidentes com o apoio da Instituição que exerce a governança da Rede. O Banco do Brasil, por exemplo, obteve ganhos com a aquisição de novos clientes. Já o representante do Sergipetec relatou os ganhos obtidos no desenvolvimento da área de pesquisas sobre biodiesel no Estado.

O aumento na capacidade de produção também foi evidente em todas as instituições estudadas. Porém, os relatos apresentaram tipos variados de ganhos obtidos pelas organizações, como, por exemplo, a influência da governança da Rede. Nesse caso, os principais relatos sobre o aumento da capacidade de produção influenciado pela governança foram: elevação da capacidade de oferta de produtos e serviços (Banco do Brasil); aumento das pesquisas (Universidade Federal de Sergipe); diversificação de processos de produção (Cooperafir); e aplicação de tecnologias na agricultura copiada para outras localidades (Sergipetec).

O representante do Sergipetec relatou que a influência da governança foi proporcionar a oportunidade para que as organizações pudessem oferecer novos produtos. Desta forma, foi evidenciado que a governança alcançou seu objetivo, já que todos os representantes confirmaram a contribuição no aumento da capacidade de produção.

Em relação ao acesso à capacitação e assistência técnica, em todos os relatos dos representantes institucionais houve a atuação da governança para a realização desse tipo de iniciativa. As informações apresentadas foram confirmadas pela Instituição governante da Rede. Nesse caso, foi informado pelo entrevistado do Sergipetec que as atividades de capacitação tiveram como objetivo contribuir com a organização do processo agrícola de matéria-prima para o biodiesel. Para essa ação, foram organizadas capacitações e dias de campo para orientação dos agricultores familiares sobre a produção de girassol. Assim, os relatos evidenciaram a contribuição da governança no processo de capacitação e assistência técnica.

A contribuição da governança da Rede Biodiesel Sergipe para a redução de custos das organizações participantes também foi evidenciada nas entrevistas. Os representantes das instituições participantes da Rede apresentaram iniciativas para a redução dos custos das organizações, como: distribuição de custos em serviços realizados de forma conjunta (Banco do Brasil), e a redução foi resultado do planejamento da produção (Cooperafir). Somente o representante da Universidade Federal de Sergipe considerou a redução de custos relativa.

O representante do Sergipetec confirmou que a redução de custos foi resultado da articulação de ações conjuntas para a realização de capacitações direcionadas aos agricultores familiares. Nesse processo, houve a distribuição dos custos entre as instituições que apoiaram tal iniciativa. Dessa forma, ficou evidente a atuação da governança. 
As contribuições da governança da Rede no processo de melhoria da gestão das organizações participantes apresentaram resultados distintos. Apenas o representante da Cooperafir informou que houve atuação direta da governança da Rede no processo de melhoria da gestão. Os demais representantes informaram que, pelo fato de as instituições já possuírem tempo de mercado e estrutura consolidada, não houve influência da governança da Rede na gestão das organizações em questão.

As informações apresentadas foram confirmadas pelo representante da Instituição governante, que relatou a utilização de ações organizadas reproduzidas pela Organização, como: planejamento das ações de capacitação em gestão e produção agrícola, além do planejamento da própria Rede.

É importante destacar que as organizações que apresentaram tal resposta (Banco do Brasil e Universidade Federal de Sergipe) foram uma autarquia federal e uma instituição financeira, o que dificulta qualquer mudança no processo de gestão.

A perpetuação do negócio foi um dos benefícios evidenciado nas entrevistas que, segundo eles, teve atuação direta na governança exercida pelo Sergipetec. Porém, apenas o representante da cooperativa agrícola relatou a contribuição da governança nesse processo. É importante lembrar que as cooperativas são as organizações com menos tempo de existência, que estão vinculadas à Rede Biodiesel Sergipe e que, também, informaram a atuação da governança no processo de melhoria da gestão dessas organizações.

O representante da Cooperafir relatou que a governança foi importante para que a organização consolidasse o processo de produção do biodiesel. Destacou, também, que a Cooperafir iniciou suas atividades quando entrou na Rede, e que a governança ajudou a dar longevidade à organização. A informação foi confirmada pelo representante da Instituição governante (Sergipetec), que relatou a atuação na consolidação das cooperativas na produção de matéria-prima para o biodiesel.

O representante do Banco do Brasil afirmou que não houve influência da governança da Rede na consolidação das atividades da Organização, pois se trata de uma empresa com tempo e experiência no mercado, em que o envolvimento na produção de biodiesel dizia respeito a mais uma entre as ações que a organização já desempenhava.

O aumento do grau de especialização também foi um dos benefícios que teve influência direta da governança da Rede Biodiesel Sergipe. Nesse caso, as principais contribuições relatadas pelos entrevistados foram alcançadas pelas organizações cooperativas e pela Universidade Federal de Sergipe. A instituição cooperativa, por exemplo, atingiu a especialização por consequência das ações de capacitação e assistência 
técnica. As informações apresentadas foram confirmadas pelo relato do representante da Instituição governante, que atuou fortemente na oferta de capacitações para as organizações cooperativas e estimulou a formação de grupos de pesquisas na Universidade Federal de Sergipe.

A contribuição da governança da Rede Biodiesel Sergipe para a maior divulgação dos produtos das organizações participantes, que resultou no aumento das vendas, também foi evidenciada nas entrevistas. O representante do Banco do Brasil, por exemplo, relatou que foi criada uma nova linha de crédito a ser oferecida aos agricultores familiares para o financiamento da produção agrícola. O representante da cooperativa informou que os produtos oferecidos pelas instituições foram apresentados aos demais parceiros da Rede, o que resultou no aumento das vendas e na prestação de serviços.

Já o representante do Sergipetec informou que a contribuição resultou no aumento das vendas por parte das cooperativas e para que os bancos tivessem a oportunidade de oferecer crédito aos agricultores familiares. Apesar de o representante em questão não relatar mais contribuições para as demais organizações, foi evidente a atuação da governança para a divulgação dos produtos e o aumento das vendas às demais instituições participantes da Rede.

Os resultados da pesquisa sobre os benefícios gerados pela governança da Rede Biodiesel Sergipe às instituições participantes têm conformidade com os estudos de Fittipaldi e Donaire (2009), que destacaram benefícios como: redução de custos, melhora na gestão do negócio, perpetuação do negócio, alto grau de especialização, maior divulgação dos produtos e aumento nas vendas.

\section{CONSIDERAÇÕES FINAIS}

O objetivo com este estudo foi analisar como a governança da Rede Biodiesel Sergipe pode apresentar diferentes contribuições à gestão em organizações parceiras, e evidenciaram-se os benefícios da governança para as organizações participantes, das mais variadas formas, mas com impactos diferentes entre as organizações. Por exemplo, o aumento no grau de especialização das organizações participantes da Rede não foi citado pela Instituição governante como foco de atuação, apesar de os relatos das instituições parceiras apresentarem informações que confirmaram essa influência. O que se pode deduzir é que a elevação do grau de especialização representou um resultado de outros benefícios já adquiridos pelas organizações. 
O resultado mais evidente foi visto na atuação da governança na melhoria da gestão das organizações. Nesse caso, foi possível perceber que a governança contribuiu diretamente para a melhoria da gestão, principalmente, das organizações com menor tempo de mercado. Entretanto, isso não foi destacado pelos representantes do Bando do Brasil e da Universidade Federal de Sergipe. No caso destas, o fato de as duas instituições terem mais tempo de mercado e, consequentemente, serem mais consolidadas, influenciou diretamente os resultados do elemento “consolidação no mercado”.

O acesso ao mercado e a assistência técnica foram mais impactantes na Instituição cooperativa, que necessitava de informações e sugestões para a organização pois possuía pouco tempo de mercado e processos produtivos ainda em evolução.

A partir das informações coletadas foi possível evidenciar que a influência da governança na perpetuação do negócio ocorreu apenas na instituição cooperativa, que possuía menos tempo no mercado em relação às demais organizações. Assim, ficou claro que a influência da governança na perpetuação do negócio das instituições parceiras esteve associada às características das organizações participantes.

Nesse sentido, a pesquisa em questão possibilitou, do ponto de vista teórico, apresentar uma perspectiva de análise para os estudos sobre governança de redes, considerando a diversidade das empresas em sua constituição e os resultados proporcionados a cada participante. É importante destacar que, a partir do momento em que benefícios diferentes são proporcionados em uma rede, isso pode, em determinado momento, ser motivo de conflitos e discussões entre seus componentes. Assim, essa perspectiva deve ser considerada e estudada.

Já do ponto de vista prático, o estudo contribuiu com relatos sobre um programa nacional de produção de insumos ligado à cadeia produtiva de biodiesel nacional, o que possibilita uma análise aprofundada sobre essa ação no Estado de Sergipe e serve como contribuição para outros estudos.

Foi possível perceber na caracterização da Rede que algumas instituições, que faziam parte da formação inicial, não foram mais citadas nos relatos dos entrevistados. Nesse sentido, para pesquisas futuras, a Rede pode ser analisada quanto ao fato de organizações terem se desligado e quanto aos tipos de relações estabelecidas entre as organizações, como formais ou informais.

Pode-se destacar como limitações da pesquisa, por meio das entrevistas, procurar-se captar informações com os entrevistados de um período superior a cinco anos, como foi o caso dos fatores internos e externos que podem ter influenciado a escolha da governança da Rede. Nesse caso, algumas informações podem ter sido omitidas ou simplesmente esquecidas pelos entrevistados. 
O tempo de cada entrevista é destacado como fator limitante, pois, em alguns casos, os pesquisados tinham pouca disponibilidade de horários para realizar as entrevistas. Dessa forma, algumas entrevistas foram realizadas em tempo muito limitado, o que contribuiu para a busca de informações mais específicas em outros meios (listas, relatórios organizacionais, atas, vídeos, entre outros).

\section{REFERÊNCIAS}

ABRAMOVAY, R.; MAGALHÃES, R. O acesso dos agricultores familiares aos mercados de biodiesel: parcerias entre grandes empresas e movimentos sociais. Londrina, 2007. Disponível em: <http://ricardoabramovay.com/o-acesso-dos-agricultores-familiares-aos-mercados-de-biodiesel-parcerias-entre-grandes-empresas-e-movimentos-sociais/>. Acesso em: 21 out. 2013.

BALESTRIN, A.; VARGAS, L. M. Evidências teóricas para a compreensão das redes interorganizacionais. In: ENCONTRO DE ESTUDOS ORGANIZACIONAIS, 2., 2002, Recife. Anais... Recife: Observatório da Realidade Organizacional: PROPAD/UFPE, ANPAD, 2002. Disponível em: < http://www.anpad.org.br/diversos/ trabalhos/EnEO/eneo_2002/2002_ENEO46.pdf>. Acesso em: 14 nov. 2012.

BRASIL. Lei n. 11.097, de 13 de janeiro de 2005. Dispõe sobre a introdução do biodiesel na matriz energética brasileira; altera as Leis $\mathrm{n}^{\text {os }} 9.478$, de 06 de agosto de 1997, 9.847, de 26 de outubro de 1999 e 10.636, de 30 de dezembro de 2002; e dá outras providências. Diário Oficial da União, Brasília, DF, 14 jan. 2005a. Disponível em: <http://www.planalto.gov.br/ccivil_03/_ato2004-2006/2005/Lei/ L11097.htm>. Acesso em: 03 dez. 2012.

BRASIL. Lei n. 11.116, de 18 de maio de 2005. Dispõe sobre o Registro Especial, na Secretaria da Receita Federal do Ministério da Fazenda, de produtor ou importador de biodiesel e sobre a incidência da Contribuição para o PIS/Pasep e da Cofins sobre as receitas decorrentes da venda desse produto; altera as Leis nos 10.451, de 10 de maio de 2002, e 11.097, de 13 de janeiro de 2005; e dá outras providências. Diário Oficial da União, Brasília, DF, 19 maio 2005b. Disponível em: <http://www. receita.fazenda.gov.br/Legislacao/leis/2005/lei11116.htm>. Acesso em: 03 dez. 2012. 
BRASIL. Ministério do Desenvolvimento Agrário (MDA). Instrução Normativa MDA n. 1, de 19 de fevereiro de 2009. Dispõe sobre os critérios e procedimentos relativos à concessão, manutenção e uso do selo combustível social. Diário Oficial da União, Brasília, DF, 25 fev. 2009. Disponível em: <http://portal.mda.gov.br/ portal/saf/arquivos/view/biodisel/IN_01_19-02-2009_Concess\%C3\%A3o.pdf>. Acesso em: 11 out. 2012.

CAMPOS, A.; CARMELIO, E. C. Biodiesel e agricultura familiar no Brasil: resultados socioeconômicos e expectativa futura. In:. FERREIRA, J. R.; CRISTO, C. M. P. N. (Org.). $\mathrm{O}$ futuro da indústria: biodiesel. Coletânea de artigos / coordenadores José Rincon Ferreira, Carlos Manuel Pedroso Neves Cristo - Brasília, DF: MDICSTI/IEL, 2006. (Série Política Industrial, Tecnológica e de Comércio Exterior, 14). Disponível em: <http://www.desenvolvimento.gov.br//arquivos/dwnl_1201279825. pdf $>$. Acesso em: 12 abr. 2013.

CASTELLS, M. A era da informação: economia, sociedade e cultura - A sociedade em rede. São Paulo: Paz e Terra, 1999.

CORREIA, L. F.; AMARAL, H. F. Reflexão sobre as funções da Governança Corporativa. Revista de Gestão USP, São Paulo, v. 13, n. 1, 2006, p. 43-55. Disponível em: http://www.google.com.br/url?sa=t\&rct=j\&q=\&esrc=s\&source=web\&c$\mathrm{d}=2 \& v e d=0 \mathrm{CDYQFjAB} \& u r l=h t t p \% 3 \mathrm{~A} \% 2 \mathrm{~F} \% 2 \mathrm{Fwww} . r e v i s t a s . u s p . b r \% 2 F r e g e \%$ 2Farticle\%2Fdownload\%2F36549\%2F39270\&ei=FGiKUt32Ioe3kQf8nYH4Cg\&usg=AFQjCNHZNUht-UOF0dmL_B55IVQFmNnRIQ\&bvm=bv.56643336,d.eW0 Acesso em: 12 out. 2013.

CORNFORTH, C. The governance of cooperatives and mutual associations: a paradox perspective. Annals of Public and Cooperative Economics, v. 75, i. 1, p. 11-32, 2004. Disponível em: <http://onlinelibrary.wiley.com/doi/10.1111/j.14678292.2004.00241.x/pdf>. Acesso em: 02 out. 2013.

CRESWELL, J. Research design: qualitative, quantitative, and mixed methods approaches. London: Sage, 2002.

CRUZ, J. A. W.; MARTINS, T. S.; QUANDT, C. O. Redes de cooperação: um enfoque de governança. Revista Alcance - Eletrônica, v. 15, n. 2, p. 190-208, maio/ago. 2008. Disponível em: <http://www6.univali.br/seer/index.php/ra/article/ view/671/543>. Acesso em: 15 dez. 2013.

EINSENHARDT, K. M. Building theories from case study research. Academy of Management Review. v. 14, i. 4, p. 532-550, 1989. 
FIGUEIREDO FILHO, W. B. Estruturas de governança, cooperação e legitimidade na construção do desenvolvimento regional. REDES, Santa Cruz do Sul, v. 20, n. 1, p. 52-68, jan./abr. 2015.

FITTIPALDI, M. A. S.; DONAIRE, D. Governança na rede de negócios do setor editorial de revistas. REGES - Revista Eletrônica de Gestão, Picos, v. 2, n. 2, p. 73-88, maio/ago. 2009.

HUMPHREY, J.; SCHMITZ, H. Governance and upgrading: linking industrial cluster and global value chain research. IDS Working Paper 120. Brighton: Institute of Development Studies, University of Sussex, 2000.

HUMPHREY, J.; SCHMITZ, H. Governance in global value chains. IDS Bulletin 32, p. 19-29, 2001.

KWASNICKA, E. L. Governança gestora na rede de negócios: um estudo comparativo. Revista Brasileira de Gestão de Negócios, v. 8, n. 21, p. 33-42, maio/ago. 2006. Disponível em: <http://www.redalyc.org/articulo.oa?id=94782105> . Acesso em: 16 ago. 2013.

LOPES, F. D.; BALDI, M. Redes como perspectiva de análise e como estrutura de governança: uma análise das diferentes contribuições. Revista de Administração Pública - RAP, Rio de Janeiro, v. 43, n. 5, p. 1007-1035, set./out. 2009. Disponível em: <http://www.scielo.br/pdf/rap/v43n5/v43n5a03.pdf>. Acesso em: 19 out. 2013.

MONTENEGRO, L. M. Um parlamento de múltiplos atores: um estudo sob a perspectiva da teoria ator-rede para o entendimento da governança e dos resultados estratégicos de Cursos de Graduação em Administração de Instituições de Ensino Superior Particulares de Curitiba. 2013. 212 p. Tese (Doutorado em Administração, Área de Concentração Estratégia e Organizações, do Setor de Ciências Sociais Aplicadas)-Universidade Federal do Paraná, Curitiba, 2013.

MUELLER, M.; SCHMIDT, A.; KUERBIS, B. Internet security and networked governance in international relations. International Studies Review, n. 15, p. 86-104, 2013. Disponível em: <http://onlinelibrary.wiley.com/doi/10.1111/misr.12024/pdf>. Acesso em: 15 dez. 2013.

NEUMAN, L. W. Social research methods: qualitative and quantitative approaches. 3. ed. Boston: Allyn \& Bacon, 1997. 
OLIVEIRA, J. L. et al. A governança corporativa como elemento mediador na empresa familiar. Revista de Administração FACES Journal, Belo Horizonte, v. 11, n. 3, jul./set. 2011, p. 105-122. Disponível em: < http://www. google.com.br/url?sa=t\&rct=j\&q=\&esrc=s\&source=web\&cd=1\&ved=0CC0QFjAA\&url=http\%3A\%2F\%2Fwww.spell.org.br\%2Fdocumentos\%2Fdownload\%2F3150\&ei=RnO9UuSyMMe-kQeX4oHoDg\&usg=AFQjCNHNDaCc3y0HIoe_4N0ruWNp5CqFSw\&bvm=bv.58187178,d.eW0>. Acesso em: 16 dez. 2013.

PARDINI, D. J.; ALVES, P. S. M.; GONÇALVES, C. A. Governança gestora: uma nova concepção na gestão de redes de pequenas e médias empresas. Revista Gestão e Planejamento, Salvador, v. 11, n. 2, p. 297-315, jul./dez. 2010. Disponível em: <http://www.revistas.unifacs.br/index.php/rgb/article/view/1133/965>. Acesso em: 16 dez. 2013.

PIRES, E. et al. As modalidades de governança territorial no Estado de São Paulo: relatório de pesquisa. Rio Claro: Unesp, 2013.

PROVAN, K. G.; KENIS, P. Modes of network governance: structure, management, and effectiveness. Journal of Public Administration Research and Theory, v. 18, i. 2, p. 229-252, 2008. Disponível em: <http://ssrn.com/abstract=1157682> ou <http://dx.doi.org/10.1093/jopart/mum015>. Acesso em: 03 set. 2013.

RHODES, R. A. W. The new governance: governing without government. Political Studies, v. 44, p. 652-667, 1996.

RHODES, R. A. W. Understanding governance: ten years on. Organization Studies, v. 28, i. 8, 2007.

RHODES, R. A. W. Waves of governance. In: LEVI-FAUR, D. (Ed.). The Oxford Handbook of Governance. Oxford: Oxford University Press, 2012.

RODRIGUES, A. L.; MALO, M. C. Estruturas de governança e empreendedorismo coletivo: o caso dos doutores da alegria. Revista de Administração Contemporânea, v. 10, n. 3, p. 29-50, jul./set. 2006.

SACHS, I. Da civilização do petróleo a uma nova civilização verde. Transcrição da palestra feita e revista pelo autor no Instituto de Estudos Avançados da USP no dia 28.6.2005. Estudos Avançados, v. 19, n. 55, 2005. 
SANTOS, M. H. C. Governabilidade, governança e democracia: criação de capacidade governativa e relações executivo-legislativo no bBrasil pós-constituinte. Dados [online], v. 40, n. 3, 1997. Disponível em: <http://www.scielo.br/scielo.php?pid=S00 11-52581997000300003\&script=sci_arttext\&tlng=es\#14>. Acesso em: 13 dez. 2013.

\section{SAUNDERS, M.; LEWIS, P.; THORNILL, A. Research methods for business} students. 4. ed. Harlow: Pearson Education, 2007.

SOUZA, Q. R.; QUANDT, C. O. Governança de redes interorganizacionais e níveis de controle formal: atividades de gestão do conhecimento em uma rede do terceiro setor. Revista Alcance, Ed. Univali, v. 14, n. 2, p. 207-230, maio/ago. 2007. Disponível em: <http://www6.univali.br/seer/index.php/ra/article/view/105/83>. Acesso em: 15 dez. 2013.

VIEIRA, J. N. S. A agroenergia e os novos desafios para a política agrícola no Brasil. In: $\mathbf{O}$ futuro da indústria: biodiesel. Brasília, DF: O futuro da indústria: biodiesel. Ministério do Desenvolvimento, Indústria e Comércio Exterior: Instituto Euvaldo Lodi/Núcleo Central, 2006.

VITAL BRAZIL, O. A. et al. Custos de transação na cadeia produtiva de biodiesel. In: CONGRESSO BRASILEIRO DE REGULAÇÃO, 6., 2009, Rio de Janeiro. Anais... Rio de Janeiro: ABAR, 2009.

VITAL BRAZIL, O. A. et al. Impactos da produção e uso de biodiesel no Estado de Sergipe. In: RIO OIL \& GAS EXPO AND CONFERENCE, 1., 2008, Rio de Janeiro. Anais... Rio de Janeiro: IBP, 2008.

WEGNER, D. Mecanismos de governança de redes horizontais de empresas: o caso das redes alemãs de grande porte. RGO -- Revista Gestão Organizacional, v. 5, n. 2, p. 214-228, jul./dez. 2012, p. 214-228. Disponível em: <http://bell.unochapeco. edu.br/revistas/index.php/rgo/article/viewFile/1398/778>. Acesso em: 16 dez. 2013.

WILLIAMSON, O. E. The economics of organization: the transaction costs approach. American Journal of Sociology, v. 87, i. 3, p. 548-577, nov. 1981.

YIN, R. K. Estudo de caso: planejamento e métodos. 4. ed. Tradução Ana Thorell. São Paulo: Bookman, 2010. 
ZYLBERSZTAJN, D.; FARINA, E. M. M. Q. Dynamics of network governance: a contribution to the study of complex forms. REAd, v. 65, i. 1, jan./apr. 2010. Disponível em: <http://www.erudito.fea.usp.br/PortalFEA/Repositorio/616/Documentos/Zylbersztajn_Farina_10_2005\%5B1\%5D.pdf>. Acesso em: 15 dez. 2013.

Como citar este artigo:

\section{ABNT}

VAZ, Vitor Hugo; OLAVE, Maria Elena Leon; BRAZIL, Osiris Ashton. Diferentes benefícios da governança na gestão de organizações de interesse público e privado: o caso da rede biodiesel Sergipe. RACE, Revista de Administração, Contabilidade e Economia, Joaçaba: Ed. Unoesc, v. 15, n. 3, p. 969-1006, set./dez. 2016. Disponível em: <http://editora.unoesc.edu.br/index.php/race>. Acesso em: dia/mês/ano.

\section{APA}

Vaz, V. H., Olave, M. E. L., \& Brazil, O. A. (2016). Diferentes benefícios da governança na gestão de organizações de interesse público e privado: o caso da rede biodiesel Sergipe. RACE, Revista de Administração, Contabilidade e Economia, 15(3), 969-1006. Recuperado em dia/mês/ano, de http://editora.unoesc.edu.br/index.php/ race 